\title{
Case study on water based cellulose couplant in contact type ultrasonic testing
}

\author{
B. Shivamurthy ${ }^{1 *}$, Krishnamurthy ${ }^{1}$ and H. K. Sachidanada ${ }^{2}$ \\ ${ }^{1}$ Department of Mechanical and Manufacturing Engineering, Manipal Academy of Higher Education \\ Manipal, India \\ ${ }^{2}$ School of Engineering and IT, Manipal University, G04, PO. Box: 345050, DIAC, Dubai, UAE
}

\begin{abstract}
In this paper the ultrasonic test performance of water based Methylcellulose couplant on steel is reported. The couplant used in the ultrasonic testing has an influence on the amplitude of the pulse echo signal. The ultrasonic energy which is transmitted from the transducer to the test material, through the couplant which is present in the interface. The amplitudes of back wall echo increases with increasing acoustic impedance of the couplant. In this research work couplant was prepared by using 0 to $50 \mathrm{~g}$ of methylcellulose in steps of $10 \mathrm{~g}$ in $250 \mathrm{ml}$ of water. All five types of water based methylcellulose couplant were used for testing a standard stainless steel calibration U2 block. The effect on the amplitudes of back wall echoes was studied and best possible combination of water and methylcellulose are reported.
\end{abstract}

Key words: Couplant, Amplitude, Ultrasonic Testing, Methylcellulose

\section{Introduction}

The contact pulse echo type ultrasonic testing has a wide range of applications such as dimensional measurements, flaw detection, medical ultrasound, sonography etc. Recently researchers given attention on influence of various parameters on test performance of ultrasonic test. The main parameters which influences the results are; instrument and transducer performance, couplant used, material variations and defect variations.

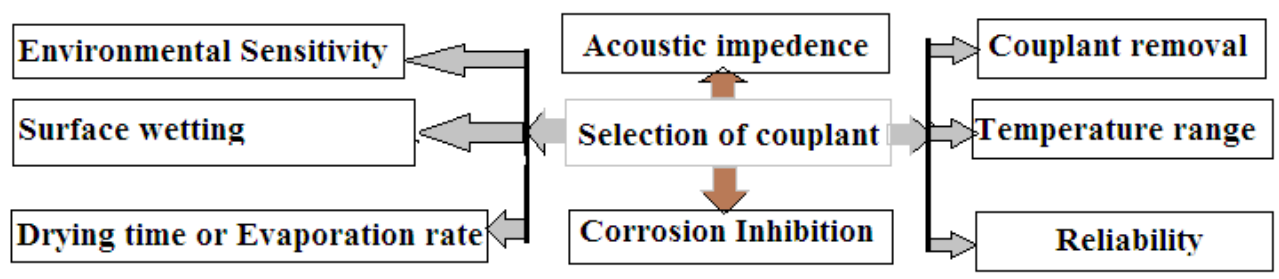

Fig. 1. Parameters to be considered for selection of couplants

\footnotetext{
* Corresponding author: b shivamurthy@yahoo.co.in
} 
A couplant is a material which is applied in between the probe and the test specimen to form a medium through which the sound waves transmit to and fro. Depending on the requirements of testing there are many suppliers who have specific couplants for specific materials. The materials were tested under controlled conditions and suggested for industrial use to get the optimum results in ultrasonic testing. The selection of couplant for ultrasonic testing is based on various parameters. Figure 1 shows the parameters to be considered while selecting the couplant. High acoustic impedance couplant reduces the surface noises and improves coupling on rough and/or curved metal surfaces. Couplant selected must be non-corrosive in nature. Higher viscosity provides good coupling and reduces surface noise. The temperature of couplant is also an important factor. The test specimen to be checked for its temperature, the area of the test specimen surface, the time required for inspection as the couplant needs to be present during the entire course of inspection. After applying couplant if the time taken for the inspection is long then the drying time is a crucial consideration. Once the inspection is completed the applied couplant must be easily removable. Couplant should be non-toxic, easy to dispose and environmental friendly. Good wetting character and the consistency of the couplant is also a desired factor. In this context few researchers worked and developed different materials for couplants and transducers. Kim Young H., et al. (2001) reported in their research about couplant effects during contact ultrasonic testing. They prepared different mixture proportions of water and glycerin as couplant and conducted ultrasonic test on carbon steel test specimen. The experiments conducted are showing different back wall echo's on the CRT screen of the ultrasonic flaw detector. They discuss also about the attenuation coefficient which is influenced by the reflection coefficient factor. Also,Vincent (1987) reported that, the amplitude of ultrasonic test signals are affected by the type of couplant used in the testing technique. Bindal (1992) reported that the petroleum products such as oils and grease as couplants over the test specimen like refractory bricks, timber, stone and civil structures leaves some marks which may be difficult to remove it later. Hence, an alternative liquid couplant is required. Ashok Kumar (1996) reported thickness measurement using ultrasonic technique. He concluded that the quality of results depends on the correction factor of the couplant being used. Bindal (2000) presented in their research that, the thicker oils, greases and viscous liquid is preferred to be applied on vertical and inclined surfaces and provide good coupling characteristics. Young H., et al. (2001) described in his research that, if the layer thickness of the couplant is applied too thin it may cause an error in the measurement of the velocity and attenuation. Kumar.et al. (2007) has discussed in his research about various coupling conditions on ultrasonic echo parameters which may have significant effects on the couplant used and their amplitude during the ultrasonic testing. They discussed various characteristics of the couplants correction factors with various test specimen thickness. Mubuza et al., (2012) reported that the reflection and transmission coefficients at the interface of transducer, couplant and specimen surface. The specimen they tried on steel and aluminum. They concluded that couplant (Honey) with high acoustic impedance and high transmission coefficients are most effective for detection of defects. Also, aluminum as low acoustic impedance as compared to steel results in back wall echoes of high amplitudes. Based on above research output in this paper a mixture of water and methylcellulose has been developed as couplants for ultrasonic testing and results are reported. 


\section{Materials and methods}

\subsection{Materials}

In this work Methylcellulose was used to prepare the couplants. Methylcellulose is easily available and generally used for adhesive purposes. Due to its adhesive nature a good coupling characteristics has been achieved. Also, it is very low environmental impact and after application it can be removed easily without leaving any marks on the test specimen. A V2-calibration block was used as a specimen to conduct ultrasonic test to evaluate effect of coupling on amplitude of back wall echoes. An ultrasonic testing machine Einstein-II TFT was used to conduct the test. A Normal probe diameter of $12 \mathrm{~mm}$ was used for generating pulse with $5 \mathrm{MHz}$ frequency.

\subsection{Couplant Preparation}

Methylcellulose is a chemical compound derived from cellulose. It is a hydrophilic white powder in pure form and dissolves in water. Methyl cellulose has lower critical solution temperature, it is between $40{ }^{\circ} \mathrm{C}$ and $50{ }^{\circ} \mathrm{C}$. At temperatures below this it is readily soluble in water. Hence, $10 \mathrm{~g}$ of Methyl cellulose was mixed with $250 \mathrm{ml}$ of water at $50^{\circ} \mathrm{C}$ by using magnetic stirrer and cooled the mixture while mixing to a lower temperature of $40^{\circ} \mathrm{C}$.Due to this the particles are dispersed uniformly and rapid dissolution was taken place. This method of mixing is repeated for different combination as shown in Table 1. Then each type of combination kept in ink filler bottle for easy application on surface of specimen.

Table 1. Composition ratio of water and Methylcellulose

\begin{tabular}{|c|c|c|}
\hline Trial No. & Quantity of water $(\mathrm{ml})$ & Quantity of Methylcellulose $(\mathrm{gm})$ \\
\hline 1 & $\mathbf{2 5 0}$ & $\mathbf{0}$ \\
\hline 2 & $\mathbf{2 5 0}$ & $\mathbf{1 0}$ \\
\hline 3 & $\mathbf{2 5 0}$ & $\mathbf{2 0}$ \\
\hline 4 & $\mathbf{2 5 0}$ & $\mathbf{3 0}$ \\
\hline 5 & $\mathbf{2 5 0}$ & $\mathbf{4 0}$ \\
\hline 6 & $\mathbf{2 5 0}$ & $\mathbf{5 0}$ \\
\hline
\end{tabular}

\subsection{Experiments and results and discussion}

The densities and the ultrasonic velocities of the prepared couplant by above mentioned method are measured. The characteristic acoustic impedance of those couplants was calculated using the measured densities and ultrasonic velocities and tabulated as shown in Table 2. It is found that the characteristic acoustic impedance increased with increased content of Methylcellulose in the water. This is because of increased viscosity and adhesive nature of the Methylcellulose in the couplant. 
Table 2. Acoustic Impedance of water based Methylcellulose couplant at different proportion.

\begin{tabular}{|l|c|c|c|c|}
\hline $\begin{array}{c}\text { Couplant } \\
\text { Code }\end{array}$ & $\begin{array}{c}\text { Combination of } \\
\text { Couplant } \\
\text { (ml. of Water +g. of } \\
\text { Methyl Cellulose) }\end{array}$ & $\begin{array}{c}\text { Density } \\
\left(\mathrm{kg} \cdot \mathrm{m}^{-3}\right) \times 10^{3}\end{array}$ & $\begin{array}{c}\text { Sound } \\
\text { Velocity } \\
\left(\mathrm{m} \cdot \mathrm{s}^{-1}\right)\end{array}$ & $\begin{array}{c}\text { Acoustic } \\
\text { Impedance } \\
\left(\mathrm{kg} \cdot \mathrm{m}^{-2} \cdot \mathrm{s}^{-1}\right) \\
\times 10^{6}\end{array}$ \\
\hline $\mathrm{C}_{1}$ & $250+0$ & 0.998 & 1490 & 1.49 \\
\hline $\mathrm{C}_{2}$ & $250+10$ & 1.019 & 1426 & 1.45 \\
\hline $\mathrm{C}_{3}$ & $250+20$ & 1.042 & 1474 & 1.46 \\
\hline $\mathrm{C}_{4}$ & $250+30$ & 1.067 & 1523 & 1.55 \\
\hline $\mathrm{C}_{5}$ & $250+40$ & 1.092 & 1567 & 1.64 \\
\hline $\mathrm{C}_{6}$ & $250+50$ & 1.119 & 1616 & 1.74 \\
\hline
\end{tabular}

Note: Acoustic Impedance of steel (Specimen V2 Block) $=Z_{3}=45.7 \times 10^{6} \mathrm{~kg} . \mathrm{m}^{-2} . \mathrm{s}^{-1}$

The probe makes direct contact with the surface of the specimen using the above mentioned coupling. The couplant thickness was maintained constant using the support of aluminum foil. An ultrasonic testing machine - Einstein -II TFT was used to excite the probe to transmit and receive the pulse echo signals on specimen. The measured signal is passed on to the flaw detectors CRT screen. The screen shots were captured and mentioned as shown in figure 3 .

Considering the first back wall echo it is found that, when using only water (without methylcellulose) i.e., $\mathrm{C}_{1}$ as a couplant (refer to figure $3(\mathrm{a})$ ) we have $10 \mathrm{~dB}$ gain when compared to the couplant mixture $\mathrm{C}_{6}$ i.e. $250 \mathrm{ml}$ of water and $50 \mathrm{gm}$ of methyl cellulose as the couplant as shown in Figure 3(f). In the Figure 3(a), since the couplant is only water the coupling nature is very good and the back wall echo is observed as $97 \%$. The amplitude of the back wall echo is much large when only water is used as a couplant. Further it is observed decrease amplitude when different proportion of methyl cellulose has been added to water and the blend was used as the couplant. The intensity of the first echoes increases with the transmission coefficient and the transmission coefficient decreased with the following consecutive echoes decrease.

In the Figure 3(b), considering the first back wall echo for analysis using couplant $\mathrm{C}_{2}$ ( $250 \mathrm{ml}$ of water and $10 \mathrm{~g}$ of methyl cellulose). It is observed a gain of $2.5 \mathrm{~dB}$ when compared to the couplant mixture $\mathrm{C}_{3}$. The couplant used is a little more viscous compared to the first couplant and the amplitude of the back wall echo observed here is $95 \%$ of the screen.

In the Figure 3(c), considering the first back wall echo for analysis using couplant $\mathrm{C}_{3}$ ( $250 \mathrm{ml}$ of water and $20 \mathrm{~g}$ methyl cellulose). It is observed a gain of $1.5 \mathrm{~dB}$ when compared to the couplant mixture $\mathrm{C}_{4}$. The couplant used is a little more viscous compared to the first couplant and the amplitude of the back wall echo observed here is $95 \%$ on the screen.

In the Figure 3(d), considered the first back wall echo for analysis when using couplant $\mathrm{C}_{4}(250 \mathrm{ml}$ of water and $30 \mathrm{~g}$ methyl cellulose). It is found that a gain of $2 \mathrm{~dB}$ when compared to the couplant mixture $\mathrm{C}_{5}$. The couplant used is a little more viscous compared to the first couplant and the amplitude of the back wall echo observed here is $90 \%$ on the screen.

In the Figure 3(e), considered the first back wall echo for analysis using couplant $\mathrm{C}_{5}$ ( $250 \mathrm{ml}$ of water and $40 \mathrm{~g}$ of methyl cellulose). It is observed a gain of $2 \mathrm{~dB}$ when compared to the couplant mixture $\mathrm{C}_{6}$. The couplant used is a little more viscous compared 
to the first couplant and the amplitude of the back wall echo observed here is $76 \%$ on the screen.

For the analysis of the first back wall echo we consider $250 \mathrm{ml}$ of water and 50 methyl cellulose as a couplant as seen in figure 3(f). The amplitude of the back wall echo is observed to be $75 \%$ on the screen.

Table 3. Calculated transmission coefficients for interfaces of the various combination of water based cellulose couplant with PZT transducer element and steel block

\begin{tabular}{|c|l|l|c|c|}
\hline Couplant Code & $\mathrm{T}_{1}$ & $\mathrm{~T}_{2}$ & Gain (Db) & $\begin{array}{c}\text { Amplitude of back wall echo } \\
(\%)\end{array}$ \\
\hline $\mathrm{C}_{1}$ & 0.0864 & 1.936 & 46 & 97 \\
\hline $\mathrm{C}_{2}$ & 0.0842 & 1.938 & 48 & 95 \\
\hline $\mathrm{C}_{3}$ & 0.0847 & 1.938 & 50.5 & 95 \\
\hline $\mathrm{C}_{4}$ & 0.0897 & 1.934 & 52 & 90 \\
\hline $\mathrm{C}_{5}$ & 0.0947 & 1.931 & 54 & 76 \\
\hline $\mathrm{C}_{6}$ & 0.1002 & 1.927 & 56 & 75 \\
\hline
\end{tabular}




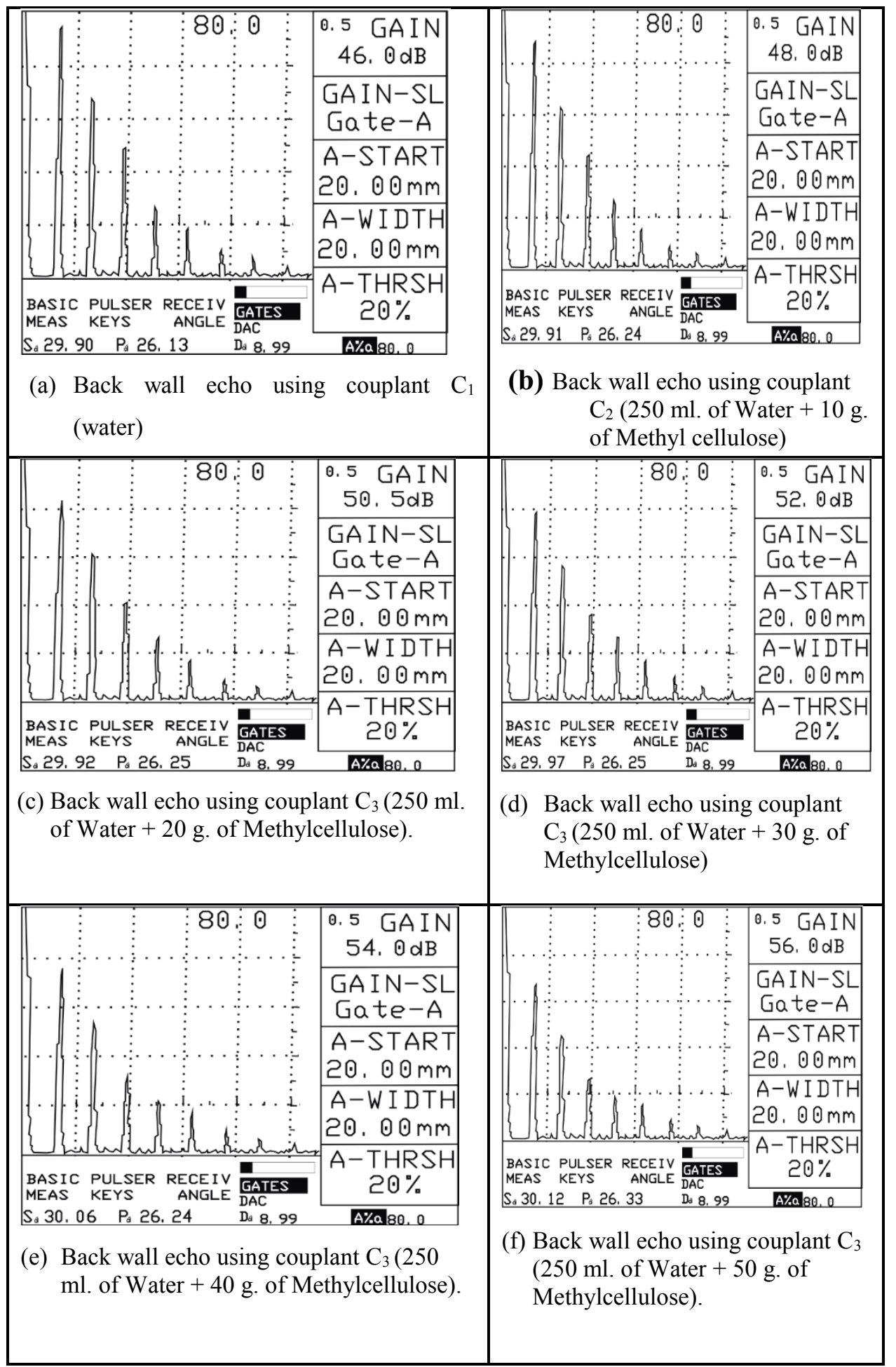

Fig. 3. Back wall echo analysis for different couplants 


\section{Conclusions}

By using the different proportions of the couplants prepared by water and methyl cellulose the ultrasonic testing is conducted by applying the couplant and their back wall echoes are measured. It is found that the amplitudes of the first back echoes and the attenuation coefficients are increased with the characteristic acoustic impedance of the couplants used. The research shows the larger the transmission coefficient and the acoustic impedance results in a higher sensitivity of the detection of the flaw in the contact pulse echo technique. Here the amplitudes of the back wall echoes are observed and their results are noted for further analysis or research when using methyl cellulose as a couplant. In industrial practice only water cannot be used as a couplant due to various factors like viscosity, corrosion etc. So there must some optimum viscosity of the couplant such that it can be applied which can withstand high temperatures, should not leave marks on the test specimen, chemically stable and should not create any impact to the environment. So with the above six couplants being used the couplant mixture $\mathrm{C} 2$ has better results having gain of decibels when compared to the couplant mixture C6 and also the amplitude of the back wall echo is observed to be $90 \%$ on the screen.

\section{References}

1. A, Kumar; N, Gupta; R, Gupta; \& Y, Kumar; Effect of coupling conditions on ultrasonic echo parameters, J. Pure Applied Ultrasonic. 2007, 27, 70-79.

2. Ashok, Kumar; Correction factor due to couplant in ultrasonic thickness measurement, Insight, UK, 1996, 38, 336-337.

3. Bindal, Arvind; A new high gain couplant for ultrasonic NDT inspection, Paper presented at National Seminar on (NDE-92). Tiruchirappalli, 1992, 3-5 Dec.

4. Bindal, V. N; Water-based couplants for general purpose use for ultrasonic NDT applications. Journal of scientific and industrial research. 2000, 59 (11), 935-939.

5. Kim, Young, H; and Song, Sung-Jin; A study on the couplant effects in contact ultrasonic testing, 10th Asia-Pacific Conference on Nondestructive Testing, Brisbane, Australia, 2001,17th -21st September.

6. Mabuza, B, R; and N; Netshidavhini; Inspection of flaws in steel using ultrasonic testing and fracture mechanics approach. Emerging Technologies in Non-Destructive Testing V 2012 (225).

7. Vincent, A; Influence of wear plate and coupling layer thickness on ultrasonic velocity measurement, Ultrasonic. 1987, 25, 237-243.

8. Young, H, Kim; Sung-Jin, Song; Sung-Sik, Lee; Jeong-Ki, Lee; Soon-Shin, Hong; A study on the couplant effects in contact ultrasonic testing, 10th APCNDT Brisbane, 2001 . 